\title{
VIDAS RURALES COMO PRODUCTO TURÍSTICO
}

\section{EL CASO DEL PROGRAMA PARAGUAYO "POSADAS TURÍSTICAS"}

\section{Montserrat Fois}

Facultad de Filosofía y Letras

Universidad de Buenos Aires.

Buenos Aires, Argentina.

(iD) 0000-0002-3123-3777

mariamontserrat.herrera@uba.com.ar

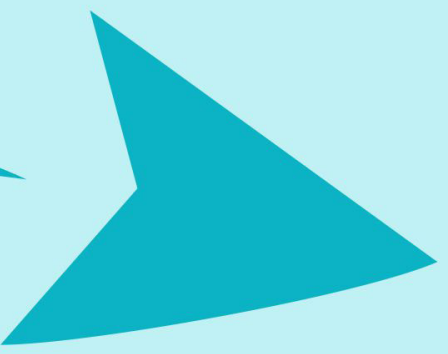

\section{RESUMEN}

El artículo tiene el objetivo de describir, desde una perspectiva socioantropológica, el modo en que el programa "Posadas Turísticas del Paraguay" promueve la puesta en valor de un conjunto de prácticas vinculadas a modos de vivir de las poblaciones que habitan zonas rurales. En ese sentido, se indaga la relación entre las políticas patrimoniales y de turismo. A su vez, se reflexiona en torno a las lógicas que subyacen a esta propuesta de puesta en valor de determinadas poblaciones, y su vida cotidiana que, en el mercado turístico, pasan a ser categorizados como experiencia. Para responder al objetivo planteado, el trabajo asume un abordaje de carácter cualitativo para el análisis de documentos y otros materiales relacionados con la política turística, en general, y con el programa, en particular. Estos datos fueron producidos por la Secretaría Nacional de Turismo (SENATUR), ente a cargo de la implementación del programa. Los resultados muestran que el programa apela a la exotización de la vida cotidiana que se desarrolla en las zonas rurales, mediante estrategias de diferenciación empleadas por el Estado que derivan en la invisibilización o profundización de desigualdades socioeconómicas.

\section{PALABRAS CLAVE}

vidas rurales $>$ experiencias $>$ políticas patrimoniales $>$ políticas de turismo $>$ Paraguay

VIDAS RURALES COMO PRODUCTO TURÍSTICO EL CASO DEL PROGRAMA PARAGUAYO "POSADAS TURÍSTICAS"

\section{Recibido}

26 de julio, 2021

Aprobado

21 de septiembre, 2021

DOI

https://doi.org/10.24215/27186717e016
Ayana Revista de Investigación en Turismo

| Año 2 | Vol. 2 | № 01 Diciembre 2021 Mayo 2022

ISSN 2718-6717

Entidad editora Instituto de Investigaciones en Turismo, Facultad de Ciencias Económicas (Universidad Nacional de La Plata) La Plata I Buenos Aires I Argentina 


\section{RURAL LIVES AS A TOURIST PRODUCT. THE CASE OF THE PARAGUAYAN PROGRAMME "POSADAS TURÍSTICAS"}

\section{ABSTRACT}

This article aims to describe, from a socio-anthropological perspective, how the Paraguayan Government's program "Posadas Turísticas" promotes the enhancement of a set of practices linked to the ways of life of the populations living in rural areas. In this sense, the relationship between heritage and tourism policies is explored. At the same time, it reflects on the rationale behind this proposal for the valorisation of certain populations and their everyday lives which, in the tourist market, are categorized as experiences. Thus, the work assumes a qualitative approach to the analysis of documents and other materials related to tourism policy in general and the programme in particular. All these data were produced by the National Secretariat of Tourism (Secretaría Nacional de Turismo, Senatur), the entity in charge of implementing the programme. The results show that the programme appeals to the exoticisation of everyday life that takes place in rural areas. This occurs through the differentiation strategies employed by the State, which lead to the invisibility or deepening of socioeconomic inequalities.

\section{KEYWORDS}

rural lives $>$ experiences $>$ patrimonial policies $>$ tourism policies $>$ Paraguay

\section{A VIDA RURAL COMO PRODUTO TURÍSTICO. O CASO DO PROGRAMA PARAGUAIO "POSADAS TURÍSTICAS"}

\section{RESUMO}

O artigo tem como objetivo descrever/o objetivo deste artigo é descrever, a partir de uma perspectiva socioantropológica, como o programa "Pousada Turística do Paraguai" promove a valorização de um conjunto de práticas vinculadas aos modos de vida das populações que habitam no meio rural. Nesse sentido, investiga-se a relação entre as políticas patrimoniais e as turísticas. Ao mesmo tempo, refletese sobre os fundamentos desta proposta de valonização de determinadas populações e de sua vida cotidiana que, no mercado turístico, são categorizadas como experiências. Para responder ao objetivo enunciado, o trabalho assume/adota uma abordagem qualitativa na análise de documentos e outros materiais relacionados à política de turismo, em geral, e com o programa em particular. Esses dados foram produzidos pela Secretaria Nacional de Turismo (Senatur), órgão responsável pela implementação do programa. Os resultados mostram que o programa apela para a exotização do cotidiano que ocome no meio rural, através de estratégias de diferenciação uilizadas pelo Estado que levam à invisibilidade ou ao aprofundamento das desigualdades socioeconômicas.

\section{PALAVRAS CHAVE}

vivências rurais $>$ experiências $>$ políticas patrimoniais $>$ políticas de turismo $>$ Paraguai 


\section{Introducción}

En el marco de la modalidad de Turismo Rural Comunitario, el plan piloto del Programa Posadas Turísticas del Paraguay fue implementado por primera vez por la Secretaría Nacional de Turismo (SENATUR), en el año 2010. Dicha implementación se realizó en la localidad de San Cosme y Damián ubicada en el departamento de Itapúa al sur del país. Desde sus inicios, el propósito del programa fue el de ampliar la oferta de alojamiento en localidades calificadas con alto potencial turístico por esta institución. Las familias de zonas rurales -y más tarde, también de zonas urbanasfueron el eje articulador de este programa. En carácter de destinatarias, las mujeres, particularmente, son categorizadas como posaderas, microempresarias y/o microemprendedoras.

La propuesta del Programa Posadas Turísticas consiste en adaptar las casas familiares de manera que funcionen también como alojamientos turísticos, y constituyan una alternativa al alojamiento hotelero, con estándares mínimos pero confiables y a bajo costo económico. Con este programa el ente de turismo apunta a producir un doble efecto de carácter económico y social. Por un lado, resolver el déficit de hospedaje registrado, lo cual constituye una condición sine qua non para atraer turistas al país. Por el otro, estimular la demanda de turismo interno en sectores con baja capacidad de gasto.

Tanto el diseño como la ejecución del plan piloto del programa se desarrollaron a partir de la cooperación técnica del Viceministerio de Industria, Comercio y Turismo de Colombia, a través del programa "Posadas Turísticas de Colombia - Infraestructura Turística y de la Agencia Presidencial de Colombia", cuya implementación en dicho país se remonta al año 2007. La experiencia colombiana fue el punto de partida para que en el año 2010 se ejecutara el plan piloto del programa, en el municipio de San Cosme y Damián. Más tarde, el mismo se expandió de manera ininterrumpida hacia otros distritos del país, hasta el presente.

Este programa, que tiene entre sus destinatarias mayoritariamente a mujeres, plantea que las casas ubicadas en potenciales destinos turísticos sean adecuadas estructural y estéticamente para el alojamiento de turistas. A criterio de la SENATUR, el principal atractivo que tienen estas posadas para el mercado nacional, pero ante todo el internacional, es que los servicios son prestados por la unidad familiar. Asimismo, se espera que se comparta el espacio físico y social con los turistas. Sostengo, en ese sentido, que desde la política pública se asume que las relaciones y prácticas que se despliegan en el ámbito doméstico rural son atractivas para el turista extranjero, al ser traducidas en clave de experiencias. Dentro de ese marco de relaciones, las mujeres son consideradas un medio por el cual esas prácticas, categorizadas como experiencias, pueden ser vehiculizadas.

Desde una perspectiva socioantropológica, las reflexiones se enmarcan en las discusiones de las políticas públicas, así como en el campo del patrimonio y el desarrollo. Los estudios antropológicos de las políticas públicas (Shore \& Wright, 2005) apuntan que la formulación y ejecución de políticas, programas y planes son una de las tantas formas en las que se expresa y se relaciona el Estado con los diversos sectores de la sociedad. Por ese motivo, constituyen una unidad de análisis privilegiada para estudiar procesos sociales, culturales e históricos más complejos. Las mismas pueden ser interpretadas según sus efectos, las relaciones que crean y los paradigmas que se ponen en juego (Shore \& Wright, 2005). A continuación, siguiendo las reflexiones de ambos autores, pretendo desplazar el foco puesto en la función 
de la política pública hacia su significado "para comprender los motivos que fundamentan dichas intervenciones y las lógicas culturales que las impulsan" (Manzano \& Ramos, 2015, p.12).

En cuanto a los debates producidos y emanados desde el campo del patrimonio y del desarrollo, considero oportuno analizar el programa a la luz de los planteamientos de George Yúdice y lo que denominó la cultura como recurso. Parafraseando al autor, a raíz de la vertiginosidad que adquirió la globalización y la dimensión que ha tomado el capitalismo, teorizó acerca del uso que determinados agentes le dan a la cultura para interferir en lo político, en lo económico y en lo social. La noción de cultura, en tanto recurso, involucra principalmente su gestión, cosa que "no era característica ni de la alta cultura ni de la cultura cotidiana entendida en un sentido antropológico" (Yúdice, 2002, p. 16). Asimismo, entre los debates sobre las políticas patrimoniales reconozco la productividad de la categoría de constructo patrimonial, empleada por Santamarina y Moncusí (2015), para pensar el programa. Esta categoría, supone que la producción de mercancías, espacios y sentidos constituyen el nuevo motor para la generación de riquezas en el capitalismo postfordista. Su utilidad radica, precisamente, en posibilitar el análisis de las formas en que determinados modos de vivir (experiencias) son susceptibles de ser empaquetados y colocados, en tanto productos, en las góndolas del mercado turístico.

En este trabajo propongo tomar el caso del programa "Posadas Turísticas" con el objetivo de describir cómo algunos territorios junto con los modos de vida de sus habitantes son puestos en valor y categorizados como experiencia en el mercado turístico. A tales fines, indago la relación entre las políticas de turismo y patrimoniales. También reflexiono acerca de las lógicas que subyacen a los procesos de puesta en valor que convierten a determinadas poblaciones - junto con sus prácticas cotidianas - en un producto dentro del mercado turístico. Con el fin de responder a los objetivos planteados, el trabajo asume un abordaje de carácter cualitativo en el análisis de documentos y otros materiales relacionados con la política turística, en general, y el programa, en particular. Dichos datos fueron producidos por la SENATUR.

\section{El contexto global y sus implicancias locales. La posición del turismo en Paraguay}

Con el golpe de estado al dictador Alfredo Stroessner, en el año 1989 en Paraguay, no solo se ponía punto final a treinta y cinco años del régimen autoritario cívico-militar, sino también se daba inicio a un largo proceso de transición democrática atravesado por grandes cambios a nivel internacional y nacional. El fin de la Guerra Fría y las reconfiguraciones políticas globales fueron acompañadas por la implementación de modelos de desarrollo basados en el neoliberalismo económico que se introdujeron con fuerza en América Latina, en la década de 1990. El primer gobierno democrático en el periodo de transición estuvo encabezado por el general Andrés Rodríguez (consuegro de Stroessner y del mismo partido político) que, junto con su sucesor, el empresario Juan Carlos Wasmosy, empezaron a poner en funcionamiento las recetas del denominado Consenso de Washington. Sin embargo, esto no significó mayores transformaciones para la economía paraguaya dado que la misma se ha caracterizado históricamente por sus fronteras abiertas y el libre comercio (Birch, 2011).

El turismo, en particular, ha tenido un valor anecdótico en el marco de la economía nacional. Desde la década de 
1970, el denominado turismo de compras se extendió considerablemente a partir de las operaciones de triangulación con Brasil y Argentina que dinamizaron el sector comercial más que la industria turística. No obstante, el turismo receptivo e interno no hayan tenido un peso considerable en el total de las exportaciones del país, mostraron un crecimiento sostenido desde principios del siglo XXI (Cabral y Schmid, 2018).

El inicio del nuevo milenio encontraba al Paraguay en una profunda crisis económica. Las altas tasas de desempleo, la pobreza creciente, la escasa inversión en obras públicas que mejoraran las condiciones de vida de amplios sectores de la población, entre otros factores, hicieron que el primer quinquenio del siglo XXI fuera ciertamente muy complejo. Desde la creación de la Red de Inversiones y Exportaciones (REDIEX) en 2004, el Ministerio de Industria y Comercio se dispuso a apoyar el desarrollo industrial a través de una mesa intersectorial destinada a reunir a los agentes públicos y privados del sector industrial, con el objetivo de aumentar la competitividad de las exportaciones de las empresas en biocombustibles, textiles y confecciones, carne y cuero y el turismo (Setrini, 2011 ). La estrategia del sector turístico impulsada desde este espacio apuntó a la promoción de Paraguay como destino turístico exponiendo la oferta turística del país a través de catálogos de venta y campañas publicitarias, haciendo especial énfasis en el turismo rural.

Según los datos disponibles, la participación del sector turístico en la economía ha mostrado un movimiento ascendente en los últimos años. En 2017, el sector turismo representó el 2,8\% del Producto Interno Bruto (PIB) que para el 2013 constituía solo el 0,94\% (Cabral \& Schmidt, 2018). Los últimos datos del 2017 muestran que el turismo se sitúa como el quinto sector exportador, antecedido por otros rubros como las semillas de soja, la energía eléctrica, la carne y las harinas de soja. Estos, significan un avance con respecto al año 2016. Así, y pese a que el turismo ha mostrado un crecimiento lento pero constante durante los últimos veinte años, no constituye una actividad productiva central para la economía paraguaya que depende de la exportación de commodities.

A escala global, el turismo ha sido considerado tanto por los organismos internacionales y las agencias de desarrollo como una actividad dinamizadora de las economías locales. Desde el 2003, la Organización de las Naciones Unidas (ONU) es, precisamente, la que adopta la denominada metodología de Turismo Pro-Pobre (PPT) en programas de turismo rural comunitario, como una herramienta de lucha contra la pobreza (Pérez Galán \& Asensio, 2012). De forma implícita, la política pública de turismo en Paraguay se ha hecho eco de ello y el programa Posadas Turísticas fue presentado también como una respuesta a la falta de trabajo en zonas rurales. Las posadas, concebidas como microemprendimientos turísticos, fueron postuladas como una forma efectiva de resolver el déficit de hospedajes en potenciales destinos turísticos y de generar, a la vez, empleos en esas poblaciones. La noción de desarrollo local cobra relevancia en el seno de este programa, pero también en las entrañas mismas de la política de turismo. Los modelos de desarrollo basados en el neoliberalismo económico (críticos a los modelos desarrollistas con fuerte injerencia del Estado) han encontrado formas de adaptar sus prácticas a los discursos del desarrollo local, otorgándole a la participación de la comunidad un rol preponderante en el marco de estas políticas que también depositan en los individuos la responsabilidad de su crecimiento económico y personal (Troncoso, 2008). Estos tuvieron acogida en el campo del turismo y se instalaron como paradigmas legitimadores de muchas acciones impulsadas para el fortalecimiento de la industria turística, y lo que diversos actores suelen denominar empoderamiento local. 


\section{La política turística y el Turismo Rural Comunitario en Paraguay}

La SENATUR es el organismo estatal a cargo de la regulación y desarrollo del sector a nivel nacional y tiene entre sus competencias:

la planificación, dirección, administración y fiscalización de todos los emprendimientos turísticos, con vistas a la generación de empleo e incremento de la renta personal con el objetivo de reducir la pobreza, y, por ende, mejorar la calidad de vida de la población. (Senatur, 2012, p. 11). ${ }^{1}$

En el año 2008, se publicó el Plan Maestro de Desarrollo Sostenible del Sector Turístico del Paraguay, para el periodo 2008-2018, cuya actualización se realizó en el año 2012. Dicho plan se constituyó en el instrumento de referencia de la política pública del sector. En un poco más de 350 páginas, este material recopila datos estadísticos, diagnósticos y actividades estratégicas para el desarrollo del turismo. El Plan Maestro fue elaborado con el objetivo general de "dotar al Paraguay una visión a largo plazo sobre el desarrollo y posicionamiento turístico y estructurar la gestión y la promoción de la actividad turística en Paraguay" (Senatur, 2012, p. 11). Siendo el desarrollo del turismo interno y receptivo la meta principal, fueron identificadas las diversas dificultades, así como también las potencialidades para lograrlo². El desarrollo y posicionamiento turístico del país debía traer aparejada la generación de riquezas, la creación de nuevos empleos y la conservación de los recursos naturales y del patrimonio cultural.

La amplitud de la política de turismo dio lugar a objetivos económicos y sociales más específicos. Entre los primeros, destaco el aumento del número de turistas y excursionistas, así como del gasto medio que estos hacen, el incremento de la oferta de alojamiento y la potenciación de las microempresas. Entre los segundos, señalo la participación de la sociedad en el desarrollo turístico, la inversión privada, extranjera y nacional, con el compromiso de producir desarrollo local; el fomento de la interrelación cultural y la identidad, la valorización de la cultura popular y la creación de puestos de trabajo locales para mitigar la pobreza, entre otros (SENATUR, 2012).

Casi a la par y en esta misma línea, la SENATUR diseñó el Plan Nacional de Turismo Rural y Comunitario, concebido como una herramienta para el impulso y la gestión de esta modalidad de turismo. Asimismo, es apreciada como una de las formas de turismo más fértiles tras el diagnóstico realizado por dicha secretaría y que se asienta en el Plan Maestro. En Paraguay, el Turismo Rural Comunitario cobró mayor relevancia en la última década a nivel institucional y, según el Plan Nacional tiene por finalidad "contribuir al progreso de las comunidades rurales cuya diversidad cultural, natural y estilo de vida comprenden un producto diferenciado" (SENATUR, 2013, p. 14). Allí, se establece que esta modalidad de turismo tiene por características distintivas, en primer lugar, el fomento del asociativismo de los pobladores locales bajo una figura legal (asociación civil sin fines de lucro, fundación, cooperativa, etc.); en segundo

' En base a la Ley N ${ }^{\circ}$ 1.388/98 del día 30 de diciembre de 1998, el Congreso de la Nación crea la estructura formal de la Secretaría Nacional de Turismo (SENATUR). Este estamento del estado, con anterioridad a la fecha de promulgación de la citada Ley, formaba parte del Ministerio de Obras Públicas y Comunicaciones (Ley 167/93). ${ }^{2}$ La Organización Mundial de Turismo (OMT) define el turismo interno como las actividades realizadas por un visitante residente en el país de referencia, como parte de un viaje turístico interno. El turismo receptor engloba las actividades realizadas por un visitante no residente en el país de referencia. 
lugar, el desarrollo de algunos de los productos o servicios mencionados en la definición de Turismo Rural. Por último, la integración en la cadena productiva de los prestadores de servicios turísticos locales, generando una oferta turística integral (SENATUR, 2013) .

El Programa Posadas Turísticas se concibió dentro de la modalidad de Turismo Rural Comunitario que a grandes rasgos implica una gestión comunitaria de los proyectos y emprendimientos turísticos que contribuya al desarrollo económico de las poblaciones rurales ${ }^{4}$. Asimismo, las posadas turísticas se inscriben dentro de la modalidad de Turismo de Pueblos, una subcategoría de la modalidad de Turismo Rural Comunitario. La SENATUR, entiende por Turismo de Pueblos a aquel que se desarrolla en los diferentes pueblos paraguayos por los pobladores locales que se dedican al turismo como actividad principal o complementaria a sus otras actividades. Agrega que en estos pueblos existe un tejido social y cultural característico de las pequeñas poblaciones paraguayas donde se destacan la gastronomía, las tradiciones y formas de vida locales. Supone, además, que junto a los atractivos turísticos naturales y el patrimonio cultural tangible e intangible que cada uno de estos pueblos posee, los pobladores permitan al visitante conocer, estar en contacto y familiarizarse con sus modos de vida (SENATUR, 2013).

El programa Posadas Turísticas se corresponde con estas modalidades de turismo en la medida no solo por desarrollarse en un ámbito rural sino que además, la SENATUR considera que el atractivo central que tienen estas posadas, tanto para el mercado nacional como el internacional, son los servicios prestados por la unidad familiar. De acuerdo a las campañas de difusión y promoción del programa, tanto la familia como el espacio rural constituyen ámbitos propicios para vivir las tradiciones y las costumbres de un lugar. Por ejemplo, en relación a las definiciones y categorizaciones presentadas, el espacio rural es construido como un objeto de consumo ideológico-cultural al ser percibido como el lugar propicio para vivir la cultura (Brac, 2011 ). Citando a Posadas, la autora continúa diciendo que las tradiciones, las costumbres y la cultura son convertidos en un producto que sale al mercado, con el nombre de experiencias. El Turismo Rural Comunitario destaca el aspecto vivencial como elemento característico y estrategia promocional presentándose como una experiencia entrelazada, inclusive, con lo íntimo.

Numerosas políticas y programas, en efecto, parten del principio de que el turismo es experiencia. Sin embargo, pocas veces problematizan qué es la experiencia y a qué se alude cuando se habla de experiencia turística en especial. La experiencia turística suele definirse como un paréntesis, una interrupción de las rutinas generalizadas de las personas; como un tiempo y espacio concretos distintos al habitual. A veces, incluso, las prácticas no difieren de aquellas que las personas realizan cotidianamente, pero se reinterpretan porque se desenvuelven en otros escenarios. Cuando una fracción del espacio se convierte en destino, en atracción turística, el tiempo de las actividades diarias se convierte en

\footnotetext{
${ }^{3}$ Según lo establecido en el Plan Nacional de Turismo Rural Comunitario, el tipo de Turismo Rural o de Estancias constituye una actividad alternativa a la actividad económica tradicional del establecimiento agropecuario. Las condiciones que deben prevalecer para calificar como tal son las siguientes: i) el alojamiento ofrecido debe estar situado en e medio rural y tiene que ser el tradicional de la zona con niveles de calidad aceptables a los segmentos del mercado prioritarios para esta actividad; ii) el propietario debe tener la mayor parte de su renta procedente de la actividad tradicional del establecimiento agropecuario; iii) la actividad agro-turística no implica un cambio en la utilización del suelo distinta a la preestablecida, sino que promueve la participación del visitante en las tareas agrícolas y/o ganaderas; iv) utiliza como bienes los productos endógenos de cada zona, tanto en la alimentación como en la artesanía; v) se ofrece al visitante la posibilidad de practicar una serie de actividades complementarias, como senderismo, cabalgatas, degustación de frutas y platos típicos de la zona, entre otros.

${ }^{4}$ Como antecedente se podría señalar que el proyecto "Desarrollo de Alojamientos Turísticos/programa Posadas Turísticas" fue diseñado y ejecutado con la cooperación del Viceministerio de Turismo de Colombia, a través del programa Posadas Turísticas de Colombia Infraestructura Turística y de Acción Social.
} 
momento de vacaciones y el Otro se transforma en representante de la sociedad local. A esa otra forma de ocupar el espacio, de emplear el tiempo y de vincularse con otros es que lo que se suele llamar experiencia turística (Vergopoulos, 2016). Por eso, al igual que el espacio y el tiempo, las interacciones producidas entre los turistas y la población anfitriona o local son consideradas como conformadoras de la experiencia turística la cual se centra en gran medida en el placer y en el conocimiento del Otro. Sin embargo, existe una multiplicidad de factores para tener en cuenta al momento de caracterizar y delimitar este tipo de experiencia.

Acotándome al programa me resulta significativo resaltar la ausencia del conflicto y de tensiones en la concepción de la experiencia turística. Así como la industria turística se encuentra popularmente asociada a los efectos positivos que puede arrojar en diferentes esferas (económica, social, cultural), sucede también con la experiencia que se deriva de la práctica turística la cual es asimilada al placer y que constituye, de algún modo, el deber ser del turismo. En ocasiones esto se desprende de una lectura que coloca a la experiencia como un proceso unilateral focalizado en el sujeto turista-cliente y no así en las denominadas poblaciones locales o anfitrionas.

En la modalidad de turismo rural la experiencia, además de placentera, es vista como la que más acerca al turista, no solo al entorno natural sino a las costumbres y modos de vivir típicos de un lugar. El espacio rural es construido como un vehículo directo al conocimiento de las tradiciones y las costumbres del destino. Al estar el espacio rural asociado a la naturaleza, a lo prístino, las poblaciones rurales que lo habitan también. Esto conduce a una cuestión muy tratada por la literatura sobre turismo y patrimonio que es la autenticidad.

Lo auténtico en el mercado turístico-patrimonial adquiere mayor relevancia. Las posadas turísticas son configuradas en ese registro donde las posadas turísticas asentadas en espacios rurales son presentadas como la puerta de entrada a lo auténtico o a la expresión más fiel de la cultura del país. En coincidencia con Santamarina y Moncusí (2015) el problema de mercantilizar lo pretendidamente auténtico en los términos del neoliberalismo es que la espectacularización o exotización y la autenticidad son dos caras de la misma moneda. La experiencia turística de la mano de estos alojamientos requiere de una narrativa que convierta lo entendido como auténtico en espectacular. El carácter performativo de la experiencia trae a la discusión su dimensión relacional, es decir, el proceso mediante el cual diversos actores intervienen para jerarquizar y caracterizar a través de ciertos elementos culturales a los espacios, las personas y a determinados hechos históricos.

\section{Las posadas turísticas algo más que una low cost}

El programa Posadas Turísticas de Paraguay forma parte de la política nacional de turismo brevemente descripta en las líneas precedentes. Bajo la gestión de la ministra Liz Cramer (2008-2012) se dirigió a poblaciones rurales y urbanas consideradas con alto valor turístico como una opción de alojamiento a bajo costo económico. La propia letra del programa define a las Posadas Turísticas como: 
viviendas típicas acondicionadas para el alojamiento de turistas. Las mismas ofrecen servicios básicos preservando las costumbres y tradiciones del país. Están pensadas para poblaciones rurales y urbanas con alto valor turístico, con la idea de ofrecer al viajero la posibilidad de vivir la cultura de las comunidades a través de las costumbres, tradiciones (gastronómicas y artesanales) y los atractivos turísticos de los diferentes destinos. De esta forma, se busca transformar todas estas experiencias en productos turísticos. (SENATUR, 2018, p. 5)

Por un lado, la definición delimita la instalación de las posadas en aquellos sitios con alto valor turístico. Al respecto, según lo establece el ente de turismo, los recursos naturales son considerados el principal atractivo turístico del país. En el Plan Maestro, estos recursos se clasifican en dos tipos: 1) recursos hídricos (ríos, arroyos, saltos, humedales y acuíferos); 2) recursos terrestres (ecorregiones como Bosque Atlántico, Cerrado, Paraguay Central, Pastizales de Mesopotamia, Chaco húmedo, Chaco seco y Pantanal) (Senatur, 2012, p. 71).

Siguiendo a Bertoncello (2009), el atractivo turístico es producto de un proceso social que otorga determinado valor a un espacio que despierta el interés de otros por conocerlo, utilizarlo o transformarlo. En otras palabras, esta asignación no es estática debido a que se construye socialmente y es constantemente reactualizada como parte de un proceso relacional. Por su parte Carenzo (2007) señala que este proceso de revalorización de la dimensión espacial suele plantearse como una recuperación "de los atributos singulares del patrimonio natural y cultural de cada territorio, así como de las potenciales capacidades (técnicas, organizativas, logísticas, comunicacionales, etc.) disponibles para explotar dichas singularidades" (p. 128). Asimismo, señala que esas interpretaciones que surgen del concepto de competitividad sistémica presuponen que "en el mundo globalizado actual los agentes económicos compiten junto a su territorio a partir de su capacidad para desarrollar productos y servicios que puedan diferenciarse territorialmente en mercados globales" (Carenzo, 2007, p. 129) 5 . Sin embargo, ambos autores coinciden en que estas singularidades no constituyen atributos inherentes de un lugar puesto que los mismos son coproducidos con la sociedad de origen de los turistas, las poblaciones locales, los hacedores de políticas públicas y los demás organismos que intervienen estos espacios (Bertoncello, 2002).

Desde esta misma perspectiva, podrían ser cuestionados los estudios y programas que presentan estos procesos de puesta en valor como un mero procedimiento técnico de detección de atractivos potenciales y naturales del lugar, como así también las concepciones sobre las políticas públicas en la medida que soslayan su carácter conflictivo, relacional y desigual. Asimismo, la letra del programa construye determinados sentidos en torno al mundo rural y asigna a las posadas el valor de constituirse en un espacio que permite vivir una experiencia o vivir la cultura, en contraposición a lo que propone la hotelería convencional internacional. En el campo del turismo, esto responde a muchos factores tales como el giro que ha dado el turismo a partir de las transformaciones socioeconómicas producto de la expansión del neoliberalismo. De este modo, el desarrollo de nuevas modalidades de turismo se dio en contraste con el turismo 
del siglo XIX, caracterizado por la afluencia de una gran cantidad de visitantes a los cuales se les ofrecía un paquete de servicios estandarizado (Bertoncello, 2002). El denominado turismo alternativo, por ejemplo, requirió de una fragmentación de los territorios y sus poblaciones promoviendo una profunda demarcación de las diferencias para llevar a las góndolas una amplia variedad de experiencias. La propuesta le atribuye valor a la experiencia de compartir la cultura de las poblaciones lejos del frío balcón de hotel cinco estrellas. En el discurso de la promoción turística de las posadas, esta experiencia incluye la gastronomía, pero principalmente, el compartir la cotidianeidad de ese Otro muy distinto al turista, exótico. En esa línea, cabe destacar que en las recomendaciones asentadas en el Plan Maestro de la SENATUR se señala que este tipo de turismo se ofrece a turistas que no pertenecen a la región dado que estos cuentan con poblaciones rurales próximas de similares características.

Esta concepción del turismo experiencial se vincula con lo que empieza a suceder desde inicios del nuevo siglo. En aquel momento, se produce una extensión de la patrimonialización monumental material de los años ochenta y noventa a la noción de patrimonio cultural inmaterial. Esto fue impulsado por UNESCO y otras instituciones multilaterales a partir de la Declaración Universal sobre Diversidad Cultural (UNESCO, 2001) y la Convención para la Salvaguardia del Patrimonio Inmaterial (UNESCO, 2003) (Pérez Galán y Asensio, 2012).

La Convención para la Salvaguardia del Patrimonio Cultural Inmaterial incluyó la categoría de patrimonio cultural inmaterial entendido por "los usos, representaciones, expresiones, conocimientos y técnicas - junto con los instrumentos, objetos, artefactos y espacios culturales que les son inherentes - que las comunidades, los grupos y en algunos casos los individuos reconozcan como parte integrante de su patrimonio cultural" (UNESCO, 2003, art. 2). El documento indica que el patrimonio cultural inmaterial se caracteriza por ser transmitido de generación en generación y recreado constantemente por las comunidades y grupos en función de su entorno, su interacción con la naturaleza y su historia, "infundiéndoles un sentimiento de identidad y continuidad y contribuyendo así a promover el respeto de la diversidad cultural y la creatividad humana" (UNESCO, 2003, art 2.1). Una aclaración que se hace en la convención es que se considerará únicamente al patrimonio cultural inmaterial y es que éste sea compatible con los instrumentos internacionales de derechos humanos existentes y con el respeto mutuo entre comunidades, grupos e individuos y de desarrollo sostenible.

En el marco de una entrevista, la directora de Patrimonio de la SENATUR remarcó que las nuevas perspectivas introducidas por la UNESCO planteaban que más allá de que el patrimonio debía cuidarse y conservarse -lo cual consideró es sumamente importante- la gente y la comunidad debían ser puestas en el centro de estos procesos. A su criterio, el programa Posadas Turísticas reviste gran importancia debido a que recupera la agenda patrimonial internacional en el marco de la política turística nacional con implicancias en varias localidades del país.

Lo anteriormente señalado puede leerse a la luz de los planteamientos realizados por George Yúdice y de lo que denominó cultura como recurso. El constructo patrimonial como centro de producción de mercancías, espacios y sentidos se ha conformado en un nuevo motor para la generación de riquezas en el capitalismo postfordista (Santamarina \& Moncusí, 2015). En el campo del turismo en particular, existe una visión sobre lo patrimonializable que lo convierte en un acto de reconocimiento, y donde el patrimonio natural y cultural forman parte de una construcción histórica y socialmente situada con fines específicos. En este sentido, la cultura y el patrimonio, entendidos como recurso, son apropiados por diversos agentes públicos, privados y comunitarios que operan en condiciones asimétricas de poder. 
En términos formales, la relación explícita entre el patrimonio y el turismo se institucionaliza cuando en el año 2012 la UNESCO conforma un espacio de turismo sostenible dentro de la Convención. Esa alianza entre la UNESCO y la Organización Mundial de Turismo (OMT) representó la voluntad de integrar el patrimonio a las políticas de desarrollo vinculadas al turismo. En el año 2012, Paraguay retoma lo pendiente respecto a lo acordado en la Convención sobre la protección del patrimonio mundial, cultural y natural (1972). La SENATUR, en conjunto con otras instituciones como la Secretaría de Cultura, establecen una serie de acciones con el fin de delinear políticas públicas que intervengan los monumentos y repercutan positivamente en las comunidades.

\section{La experiencia como producto}

Las transformaciones socioeconómicas producidas con la expansión del neoliberalismo han tenido sus efectos en los mercados de trabajo de los diferentes países. En el caso del turismo, este contexto dio lugar al desarrollo de nuevas modalidades de turismo en detrimento del turismo masivo (Bertoncello, 2002). Por esta razón, el surgimiento del turismo alternativo respondió no solo a demandas específicas, sino que expresaron cambios en los modelos de desarrollo y en las sociedades.

Con la explosión de la industria del turismo global en la última década del siglo XX se produjo un crecimiento del consumo patrimonial (Torres Fernández, 2008). La economía globalizada caracterizada por la tercerización y deslocalización de la producción forzó a los centros clásicos de producción como a las periferias a reinventarse. La incorporación de lo inmaterial a la lista de lo patrimonializable por parte de la UNESCO, puede ser leída en el marco de la transformación de la racionalidad neoliberal, entendiendo que el capitalismo en su fase neoliberal centra la mirada en la producción de valor de lo inmaterial (Santamarina \& Moncusí, 2015).

El turismo encontró en el patrimonio su par perfecto. Su crecimiento en el capitalismo postfordista trajo consigo un mercado cuyas exigencias se vinculan con un tipo de turismo natural y cultural que adquiere características específicas en un contexto de producción de capitales transnacionales. Dado que las zonas rurales se encuentran, generalmente, en la periferia de los centros de producción y que la situación socioeconómica opera como condicionante, el turismo rural comunitario se abrió camino ofreciendo al consumidor productos categorizados como naturales, tradicionales, auténticos.

En el marco de la modalidad de Turismo Rural Comunitario, la implementación del programa Posadas Turísticas se propone el rescate y la puesta en valor de la cultura. En este sentido, lo tradicional y las formas de ser o de vivir del paraguayo (en masculino) son centrales para garantizar el objetivo de esta modalidad turística, a saber, el desarrollo local y sostenible, a través del empoderamiento de las comunidades.

La cultura tiene un lugar y un papel asignados en este tipo de proyectos que promueven el desarrollo, lo cual ha motivado estudios desde múltiples abordajes. En el neoliberalismo, programas como el que aquí exploro resultan de gran importancia por el activo rol que desempeñan en procesos de exotización de aspectos culturales y de consolidación de un tipo de identidad nacional. Como señalé anteriormente, la industria turística se ha esforzado en la demarcación de las diferencias fomentando la curiosidad por esos Otros que son representados como la suma de ciertas características que pueden empaquetarse para luego ser colocadas en las góndolas del mercado turístico. 
El enfoque de la cultura como recurso para el desarrollo ingresó a América Latina de la mano de políticas públicas, en un momento en el que la agenda de los países centrales y de los organismos internacionales se focalizaba en generar desarrollo en los países del Tercer Mundo. La modalidad de Turismo Rural Comunitario, que contó con muchos adeptos en países latinoamericanos, apunta a la experiencia, a la cercanía del turista con la comunidad anfitriona mediante la posibilidad de compartir su cultura, sus costumbres y tradiciones.

Imbuido el programa por esa modalidad, una casa apta para operar como posada turística debe responder a determinados parámetros en términos estéticos. Sin embargo, también debe adaptar las dinámicas al interior del espacio doméstico donde se genera un proceso por el cual quienes la habitan deben exotizar su vida cotidiana, es decir, extrañarse de sus propios modos de vida o bien, encarnar y reforzar las diferencias para convertirlas en un producto comercializable. Según Margaret Swain (2005), "el turismo es una industria que se monta sobre las diferencias entre paisajes, pueblos y experiencias" (p. 30).

Los agentes estatales toman elementos que consideran manifestaciones fieles de lo que identifican como parte de la cultura paraguaya entre los que aparecen un tipo de gastronomía, formas de habitar y de relacionarse. A la par, recuperan estos elementos y con ello construyen un nosotros nacional homogéneo y monolítico para exportar al mundo con la colaboración del marketing turístico. En el caso del programa, esa construcción del nosotros remite a una homogeneidad aparentemente indiscutible y a características presentadas como inherentes del habitar zonas rurales y, por ende, del ser paraguayo. A modo de ilustrar este punto cabe destacar que en el marco de la Feria Internacional de Turismo (FITUR) en su edición del año 2017 en Madrid, el programa recibió el Premio Excelencias turísticas precisamente por "favorecer la preservación de las costumbres y las tradiciones del país" (Agencia de Información Paraguaya, 2017).

Un punto central en el análisis del programa guarda relación con las dinámicas patrimoniales y los cambios producidos en la concepción hegemónica de patrimonio cultural centrados en "las formas materiales del patrimonio nacional como expresión del Estado nación moderno" (Benedetti, 2019, p. 3). La puesta en vigencia de la categoría patrimonio intangible dio un marco donde, incluso, los modos de vida de la gente se convirtieron en productos comercializables. En la letra de la política y en los discursos en torno a ella se configuran Otros rurales lejanos, con modos de vidas distintos a las del turista, aparentemente inalterables en el tiempo y dignos de ofrecerse en el mercado turístico. Las diferencias culturales son celebradas y se vuelven mercancía mientras que, en contrapartida, las desigualdades sociales, económicas y de género son ocultadas o, al menos, invisibilizadas.

\section{Conclusiones}

En el presente articulo propuse describir cómo desde el programa Posadas Turísticas la SENATUR busca valorizar, junto con el espacio físico, un conjunto de prácticas vinculadas a modos de vivir particulares de las poblaciones que lo habitan. En el mercado turístico, dichos modos son categorizadas como experiencia. Para ello, analicé la relación entre las políticas patrimoniales y las de turismo en un contexto más amplio.

A partir del programa Posada Turística, se pudo ver la manera en que la política de turismo se entreteje con las políticas patrimoniales en Paraguay. Asimismo, las modificaciones producidas en las lógicas patrimoniales pueden 
comprenderse en clave del modelo de desarrollo y la dinámica del capitalismo. La incorporación del patrimonio cultural inmaterial expresa una adaptación del capitalismo para seguir extrayendo valor económico, esta vez a partir de la construcción de nuevas formas de consumo de la cultura y de aprovechar, en muchos casos, las desigualdades sociales y económicas.

Desde el programa se jerarquiza el mundo rural, asociándolo como el espacio donde se expresa más fielmente la cultura al igual que los modos de vivir de quienes allí residen. Considerando las definiciones y categorizaciones realizadas por dicha institución, es factible identificar que se basen, en gran medida, en la idea de que la familia y el espacio rural constituyen ámbitos propicios para vivir las tradiciones y las costumbres del país. En contrapartida, estos programas y discursos terminan soslayando las profundas desigualdades territoriales, sociales y económicas que afectan a una parte fundamental en el desarrollo del turismo. En este sentido, sostuve al inicio que el programa promueve una exotización de la vida cotidiana en el mundo rural al comercializarla bajo la etiqueta de experiencia. Hablo de exotización en la medida que, y siguiendo a García Canclini (2004), el programa convierte en producto turístico la vida cotidiana en ámbitos rurales, mediante estrategias de diferenciación empleadas por el Estado, así como de invisibilización o profundización de las desigualdades.

\section{Referencias bibliográficas}

Agencia de Información Paraguaya (2017). Paraguay recibe "Premio Excelencias" por el servicio de las Posadas Turísticas. IP. Agencia de Información Paraguaya. https://www.ip.gov.py/ip/paraguay-recibe-premio-excelencias-por-el-servicio-de-las-posadas-turisticas/.

Benedetti, C. (2019). De la "industria del piquete" al "paraíso verde". Turismo y pueblos originarios en un municipio del norte argentino. Revista de Antropología Social, 28(1), 1-21. http://dx.doi.org/10.5209/RASO.63764

Bertoncello, R. (2002). Turismo y territorio. Otras prácticas, otras miradas. Aportes y Transferencias, 6(2), 29-50.

Bertoncello, R. (2009). Presentación. En R. Bertoncello (comp.) Turismo y geografía. Lugares y patrimonio natural-cultural de la Argentina. Buenos Aires: Ciccus.

Birch, M. (2011). Generando crecimiento sustentable en un contexto democrático 1989-2009. En D. Borda \& F. Masi (eds.) Estado y Economía en Paraguay 1870-2010. Centro de Análisis y Difusión de la Economía Paraguaya, 247-287.

Brac, M. (2011). Patrimonio cultural y turismo emergente: Villa Guillermina, de pueblo obrero a nuevo destino turístico. Un estudio de caso. Cuadernos de Antropología Social 33, 11 1-128.

Cabral, A. \& Schmidt, E. (2018). Turismo receptivo en el Paraguay: una reseña de su aporte a la economía durante el periodo 2003-2017. Turismo \& Sociedade, 11 (3), 453-471. 
Carenzo, S. (2007). Territorio, identidades y consumo: reflexiones en torno a la construcción de nuevos paradigmas en el desarrollo. Cuadernos de Antropología Social 26, 125-143.

García Canclini, N. (2004). Diferentes, Desiguales y Desconectados. Mapas de la Interculturalidad. Barcelona: Gedisa.

Manzano, V. \& Ramos, A. (2015). Introducción. Procesos de movilización y de demandas colectivas: estudios y modos de abordar "lo políicico" en la vida social. Identidades, 5(8), 1-25.

Santamarina, B. \& Moncusí, A. (2015). El mercado de la autenticidad. Las nuevas ficciones patrimoniales. Revista de Occidente, 410(11), 93-112.

SENATUR (2012). Plan Maestro de Desarrollo Sostenible del Sector Turístico de Paraguay (2012 - 2018).

SENATUR (2013). Plan Nacional de Turismo Rural Comunitario. OKARA ATY M BA'E.

SENATUR (2018). Manual de Buenas Prácticas de las Posadas Turísticas. Asunción: Secretaría Nacional de Turismo.

Setrini, G. (2011). Veinte Años de Democracia Electoral en Paraguay. Del Clientelismo Monopólico al Clientelismo Plural. En D. Boda \& F. Masi. Estado y Economía en Paraguay 1870-2010. Centro de Análisis y Difusión de la Economía Paraguaya, 332-401.

Shore, C. \& Wright, S. (2005). Introduction: Policy: A new field of anthropology. En C. Shore \& S. Wright (eds). Anthropology of Policy Critical perspectives on governance and power. New York: Routledge.

Swain, M. (2005). Las dimensiones de género en la investigación sobre turismo: temas globales, perspectivas locales. Política y sociedad, 42(1), 25-37.

Pérez Galán, B. \& Asensio, R. (2012). Introducción. En ¿̇El turismo es cosa de pobres? Patrimonio cultural, pueblos indígenas y nuevas formas de turismo en América Latina. Revista PASOS e Instituto Peruano de Antropología, 8, 1-14.

Torres Fernández, P. (2008). Redefiniendo alteridades. Políficas provinciales de turismo étnico en Chaco y Formosa [Ponencia]. IX Congreso Argentino de Antropología Social. Facultad de Humanidades y Ciencias Sociales - Universidad Nacional de Misiones, Posadas.

Troncoso, C. (2008). Turismo, desarrollo y participación local. La experiencia de Quebrada de Humahuaca - Jujuy. Aportes y Transferencias, 2(12).

UNESCO (17 de octubre al 31 de noviembre de 1972). Convención sobre la Protección del Patrimonio Mundial Cultural y Natural. París. 
UNESCO (15 de octubre al 3 de noviembre de 2001). Declaración Universal sobre Diversidad Cultural. París.

UNESCO (17 de octubre de 2003). Convención para la Salvaguardia del Patrimonio Inmaterial. París.

Vergopolous, H. (2016). L'expérience touristique: une expérience des cadres de l'expérience touristique? Via. Tourism Review (10).

Yúdice, G. (2002). El Recurso de la Cultura. Usos de la cultura en la era global. Barcelona: Gedisa. 